\title{
Post Severe Acute Respiratory Syndrome Coronavirus 2 Infection Tremors in a Nonverbal Autistic Adolescent
}

\author{
Alexandra Zariffeh ${ }^{1}$, Ahmed S. Youssef ${ }^{1}$, Firdous Rizvi ${ }^{2}$, Lily Q. Lew ${ }^{1}$ \\ 1. Pediatrics, Flushing Hospital Medical Center, New York City, USA 2. Pediatric Neurology, Flushing Hospital Medical \\ Center, New York City, USA
}

Corresponding author: Lily Q. Lew, llew2.flushing@jhmc.org

\begin{abstract}
Severe acute respiratory syndrome coronavirus 2 (SARS-CoV-2) causing coronavirus disease 2019 (COVID19) pandemic in 2020 remains a major public health challenge until mass vaccination. The number of SARSCoV-2 positive children aged 0-17 years has been increasing as older adults are vaccinated. Infected children tend to have less severe illness compared with adults, have predominantly respiratory or GI symptoms, or no symptoms. Children have an increased risk for multisystem inflammatory syndrome in children (MIS-C), which is unique. Neuropsychological complications of COVID-19 remain uncommon. Case reports and data from series exist. We report a case of tremors as sequelae of SARS-CoV-2 infection in a non-verbal
\end{abstract} adolescent with autism spectrum disorder (ASD).

Categories: Neurology, Infectious Disease

Keywords: post-covid-19, tremors, adolescent, autism spectrum disorder and emotion, covid 19

\section{Introduction}

Severe acute respiratory syndrome coronavirus 2 known as SARS-CoV-2 is the cause of coronavirus disease 2019 or COVID-19 [1]. Children and adolescents infected with SARS-CoV-2 are often asymptomatic and may have milder and atypical symptoms compared to adults [2]. Symptoms commonly reported in SARS-CoV-2 infection include fever, cough, and difficulty in breathing [3]. Neuropsychological symptoms spanning the spectrum from loss of smell to encephalopathy in the critically ill during the acute phase of infection remain uncommon [4]. Possible etiology of neuropsychological symptoms includes direct viral invasion or secondary to inflammation and hypoxia of the brain [5]. Neuropsychological symptoms in months after SARS-CoV-2 infection are emerging as either persistent or nouveau in one out of three patients [6]. We describe a case of tremors as sequelae of SARS-CoV-2 infection in a nonverbal adolescent with autism spectrum disorder (ASD).

Review began 06/22/2021 Review ended 06/30/2021 Published 07/10/2021

(c) Copyright 2021

Zariffeh et al. This is an open access article distributed under the terms of the Creative Commons Attribution License CC-BY 4.0., which permits unrestricted use, distribution, and reproduction in any medium, provided the original author and source are credited.

\section{Case Presentation}

An 11/12-year-old nonverbal Hispanic male with known ASD was admitted with a two-week history of intermittent tremors of all four extremities throughout the day. The tremors lasted minutes, and on several occasions, terminated with non-stimulated ejaculation. He had no fever, seizure-like activity, or changes in appetite, diet, bowel habits, or level of activity. During the same period, he had profuse perspiration during sleep. The parents sensed anger and possible pain from his change in behavior when having tremors. After one week of symptoms, he was evaluated by his primary care provider and was prescribed hydroxyzine hydrochloride for five days without improvement. Three months prior to this admission, he was admitted with GI symptoms. He was observed for multisystem inflammatory syndrome in children (MIS-C) after testing SARS-CoV-2 positive. Since his initial hospitalization, he became withdrawn and was requesting more hugs from his mother. His weight was 118.8 kilograms, height 176 centimeters, BMI $38.6 \mathrm{~kg} / \mathrm{m} 2$ (obese, class II), blood pressure $127 / 79 \mathrm{~mm} \mathrm{Hg}$, pulse 95 beats per minute, temperature $36.7^{\circ}$ celsius and oxygen saturation $97 \%$ in room air. The facies were not dysmorphic and the thyroid was not enlarged. The heart and lung examinations were normal. There was right upper quadrant tenderness on palpation of the abdomen. Tremors of extremities appeared uncontrolled, coarse, at rest, increased with pain, and decreased with relaxation. A finger-to-nose test was performed without shaking fingers. There were no focal sensory or motor deficits on neurological examination.

Electroencephalogram showed normal brain wave activity. MRI without contrast revealed a tiny focus of increased diffusion-weighted imaging (DWI) signal in the left anterolateral aspect of the proximal cervical spinal cord at $\mathrm{C} 1$ level, no hemorrhage, edema, or focal lesion in brain parenchyma. ECG tracing showed sinus tachycardia and nonspecific T-wave abnormality. The radiograph of the chest was normal. The abdominal sonogram was consistent with hepatomegaly and hepatic steatosis. Laboratory tests are shown in Table 1 . 


\section{Cureus}

\begin{tabular}{|c|c|c|c|}
\hline Name of the test (units) & Hospitalization \#1 & Hospitalization \#2 & Reference range \\
\hline Alanine aminotransferase ( $\mu \mathrm{kat} / \mathrm{L})$ & 2.07 & 184 & $0.15-0.40$ \\
\hline Amylase $(\mu \mathrm{kat} / \mathrm{L})$ & 0.78 & 0.95 & $0.42-169$ \\
\hline Antinuclear antibodies & & Negative & Negative \\
\hline Aspartate aminotransferase $(\mu \mathrm{kat} / \mathrm{L})$ & 0.87 & 1.04 & $0.22-0.43$ \\
\hline Bilirubin $(\mu \mathrm{mol} / \mathrm{L})$ & 25.65 & 18.81 & $0.11-7.18$ \\
\hline Brain natriuretic peptide $(\mathrm{ng} / / \mathrm{L})$ & 32 & 14 & $0-125$ \\
\hline Calcium (mmol/L) & 2.22 & 2.52 & $1.22-1.37$ \\
\hline Ceruloplasmin (mg/L) & & 270 & $200-450$ \\
\hline Copper ( $(\mu \mathrm{mol} / \mathrm{L})$ & & 15.8 & $12-29$ \\
\hline C-reactive protein (mg/L) & $<0.5$ & 0.7 & $0.1-1.7$ \\
\hline Creatine kinase-MB $(\mu \mathrm{g} / \mathrm{L})$ & & 1 & $0-3.3$ \\
\hline Creatine phosphokinase ( $\mu$ kat/L) & & 10.1 & $1.13-15.2$ \\
\hline D-dimer (nmol/L) & 867.5 & & $<1250$ \\
\hline Erythrocyte sedimentation rate $(\mathrm{mm} / \mathrm{hr})$ & 2 & & $0-10$ \\
\hline Glucose (mmol/L) & 6.05 & 5.99 & 4.1-6.1 \\
\hline Hemoglobin $(\mathrm{g} / \mathrm{L})$ & 162 & 168 & $112-165$ \\
\hline Hemoglobin A1c (\%) & & 5.10 & 5.7-6.4 \\
\hline Insulin (pmol/L) & & 357 & 208-1597 \\
\hline Lead $(\mu \mathrm{mol} / \mathrm{L})$ & & $<0.048$ & 0.067 \\
\hline Lipase $(\mu \mathrm{kat} / \mathrm{L})$ & 1.95 & 1.97 & $0.07-0.65$ \\
\hline Magnesium (mmol/L) & & 0.86 & $0.86-1.17$ \\
\hline Phosphorus (mmol/L) & & 1.45 & $0.9-1.6$ \\
\hline SARS-CoV-2 & Positive $^{*}$ & Negative $^{\Theta}$ & Negative \\
\hline Thyroxine, total (nmol/L) & & 135.1 & $65.1-132.5$ \\
\hline Triiodothyronine, total (nmol/L) & & 2.36 & $0.053-0.061$ \\
\hline Thyroid-stimulating hormone (mlU/L) & & 2.84 & $0.45-4.50$ \\
\hline Troponin-I ( $\mu \mathrm{g} / \mathrm{L})$ & $<0.012$ & $<0.012$ & $0-0.4$ \\
\hline Toxicology (urine) & & Negative & Negative \\
\hline Vanillylmandelic acid ( $\mu \mathrm{mol} / \mathrm{d})$ & & 15.6 & 10.1-35.5 \\
\hline Vitamin $B_{12}(p m o l / L)$ & & 286 & $150-599$ \\
\hline Vitamin D (25OH) (nmol/L) & & 37.75 & $>50$ \\
\hline White blood cell count $\times 10^{\%} / \mathrm{L}$ & 8.5 & 10.2 & $3.5-12.0$ \\
\hline
\end{tabular}

TABLE 1: Laboratory findings.

*ID NOW COVID-19 test, @RNA-RT CoVID-19 test.

\section{Discussion}

SARS-CoV-2 infection in children aged 0-17 years has been increasing as older adults become vaccinated [7]. 
COVID-19 vaccines are approved for emergency use in children older than 12 years and for younger children forthcoming [8]. Infected children tend to have less severe illnesses compared with adults, have predominantly respiratory or GI symptoms or no symptoms [9]. Unique to the pediatric population is MIS-C. One out of three patients recovering from SARS-CoV-2 infection could experience neurological or psychological after-effects as lasting impact on the brain such as headaches, dizziness, anosmia, ageusia, cognitive impairment, muscle weakness, and tremors [10-13]. Etiologies of neurological symptoms have been postulated to include direct viral invasion, secondary inflammation, and hypoxia [5]. A tremor in children, as in this case remains uncommon, accounting for $10-20 \%$ of pediatric movement disorders and increases with age. Tremor appears to be rhythmic, involuntary, and to-and-fro movement of one or more parts of the body that can be triggered by stress, fatigue, and strong emotion as in fear and anxiety. Psychogenic tremor or functional tremor is the likely cause of the tremor in our patient. Functional tremor has an abrupt onset, tends to affect all body parts, increases in times of stress, and decreases when distracted and relaxed [13]. Other etiologies of tremors in children include Wilson's disease, Fragile X syndrome, nutritional deficiencies, thyroid dysfunction, and heavy metal poisoning [14]. All biochemical and imaging studies excluded all known causes of tremor. Whether post-viral infection injury to the brain evaded detection with present imaging studies remains to be determined.

According to the Centers for Disease Control and Prevention, the prevalence of ASD is estimated in one in 54 children and four times higher among boys than girls. Less than half of individuals with ASD are nonverbal and a third have intellectual disabilities. Children with ASD often have difficulty managing emotions and exhibit self-stimulating behavior. Our patient was neurologically and psychologically intact at the time of the first hospitalization for possible MIS-C. Hospitalization \#1 was a change in a familiar place and persons for this adolescent with ASD. Stress, fear, and isolation due to COVID-19 provided trauma to the body. The acute onset of behavior changes and specific description of tremors two months after SARS$\mathrm{CoV}-2$ infection excluded all chronic causes of tremor. Hydroxyzine hydrochloride was prescribed to relieve anxiety and tension and was not the cause of trembling and shaking.

\section{Conclusions}

We conclude after a detailed and exhaustive diagnostic workup that the tremor exhibited by our patient was a psychological symptom resembling a neurological condition. The psychological nature of the tremor was confirmed by cessation of all movements post ejaculation and with relaxation. Our patient was nonverbal and unable to express or elaborate his feelings, thoughts, and needs. Children with ASD are equally vulnerable to psychological reactions to COVID-19. Healthcare providers who care for children with ASD should be aware of psychological trauma manifesting as a neurological condition during and post SARSCoV-2 infection.

\section{Additional Information \\ Disclosures}

Human subjects: Consent was obtained or waived by all participants in this study. Conflicts of interest: In compliance with the ICMJE uniform disclosure form, all authors declare the following: Payment/services info: All authors have declared that no financial support was received from any organization for the submitted work. Financial relationships: All authors have declared that they have no financial relationships at present or within the previous three years with any organizations that might have an interest in the submitted work. Other relationships: All authors have declared that there are no other relationships or activities that could appear to have influenced the submitted work.

\section{References}

1. World Health Organization. 2020. Novel Coronavirus (2019-nCoV). Situation report 1, 21 January 2020 . (2020). https://www.who.int/docs/default-source/coronaviruse/situation-reports/20200121-sitrep-1-2019ncov.pdf.

2. Bialek S, Gierke R, Hughes MM, McNamara LA, Pilishvili T, Skoff T: Coronavirus disease 2019 in Children United States, February 12-April 2, 2020. MMWR Morb Mortal Wkly Rep. 2020, 69:422-426. 10.15585/mmwr.mm6914e4

3. COVID-19 in Children and Teens . (2021). https://www.cdc.gov/coronavirus/2019-ncov/daily-lifecoping/children/symptoms.html.

4. Filatov A, Sharma P, Hindi F, Espinosa PS: Neurological complications of coronavirus disease (COVID-19): encephalopathy. Cureus. 2020, 12:e7352. 10.7759/cureus.7352

5. Pezzini A, Padovani A: Lifting the mask on neurological manifestations of COVID-19. Nat Rev Neurol. 2020, 16:636-644. 10.1038/s41582-020-0398-3

6. Taquet M, Geddes JR, Husain M, Luciano S, Harrison PJ: 6-month neurological and psychiatric outcomes in 236379 survivors of COVID-19: a retrospective cohort study using electronic health records. Lancet Psychiatry. 2021, 8:416-427. 10.1016/S2215-0366(21)00084-5

7. Sisk B, Cull W, Harris JM, Rothenburger A, Olson L: National trends of cases of COVID-19 in children based on US State Health Department Data. Pediatrics. 2020, 146:e2020027425. 10.1542/peds.2020-027425

8. COVID-19 Vaccines for Children and Teens . (2021). https://www.cdc.gov/coronavirus/2019ncov/vaccines/recommendations/adolescents.html.

9. Shekerdemian LS, Mahmood NR, Wolfe KK, et al.: Characteristics and outcomes of children with 


\section{Cureus}

coronavirus disease 2019 (COVID-19) infection admitted to US and Canadian pediatric intensive care units. JAMA Pediatr. 2020, 174:868-873. 10.1001/jamapediatrics.2020.1948

10. Lüers JC, Klußmann JP, Guntinas-Lichius O: [The COVID-19 pandemic and otolaryngology: what it comes down to?]. Laryngorhinootologie. 2020, 99:287-291. 10.1055/a-1095-2344

11. Tsai L-K, Hsieh S-T, Chao C-C, Chen Y-C, Lin Y-H, Chang S-C, Chang Y-C: Neuromuscular disorders in severe acute respiratory syndrome. Arch Neurol. 2004, 61:1669-1673. 10.1001/archneur.61.11.1669

12. Chen T-H: Neurological involvement associated with COVID-19 infection in children . J Neurol Sci. 2020, 418:117096. 10.1016/i.jns.2020.117096

13. Piscitelli D, Perin C, Tremolizzo L, Peroni F, Cerri CG, Cornaggia CM: Functional movement disorders in a patient with COVID-19. Neurol Sci. 2020, 41:2343-2344. 10.1007/s10072-020-04593-1

14. Crawford P, Zimmerman EE: Tremor: sorting through the differential diagnosis . Am Fam Physician. 2018, 97:180-186. 